\title{
Statin Treatment, Carotid Atherosclerotic Plaque Macrophage Infiltration and Circulating Inflammatory Markers
}

\author{
Michael Koutouzis ${ }^{1}$, Kosmas I. Paraskevas ${ }^{*}$, , Loukianos S. Rallidis ${ }^{3}$, Calypso Barbatis ${ }^{4}$, Alexandros \\ Nomikos $^{4}$, Vasiliki Tzavara ${ }^{5}$, Maria Tsopanomichalou ${ }^{4}$, Christos Lioupis ${ }^{2}$, Nikolaos Bessias, \\ Vassilios Andrikopoulos ${ }^{2}$, Dimitri P. Mikhailidis ${ }^{6}$ and Zenon S. Kyriakides ${ }^{1}$
}

\begin{abstract}
${ }^{l} 2^{\text {nd }}$ Department of Cardiology, ${ }^{2}$ Department of Vascular Surgery, ${ }^{4}$ Department of Histopathology and ${ }^{5} 1^{\text {st }}$ Department of Internal Medicine, Red Cross Hospital, Athens, Greece; ${ }^{3} 2^{\text {nd }}$ Department of Cardiology, Attikon University Hospital, Athens, Greece; ${ }^{6}$ Department of Clinical Biochemistry (Vascular Disease Prevention Clinics) and Dept. of Surgery, Royal Free Hospital campus, University College London (UCL), London, UK
\end{abstract}

\begin{abstract}
Backround: Statin treatment is considered as first line therapy in patients with atherosclerotic disease. We evaluated the effect of pre-treatment with statins on carotid plaque infiltration by macrophages and on the circulating levels of proinflammatory cytokines in patients who underwent carotid endarterectomy.

Patients and Methods: One hundred fourteen patients were enrolled; 89 men and 25 women (mean age $67 \pm 8$ years; range $42-83$ years). Fifty three patients (46\%) were on statin treatment at least 3 months before endarterectomy and 61 (54\%) had never received statin treatment. The serum levels of high sensitivity $\mathrm{C}$ reactive protein (hsCRP), serum amyloid A (SAA), tumor necrosis factor $\alpha(\mathrm{TNF} \alpha)$, interleukin (IL)-1 $\beta$ and IL-6 were evaluated preoperatively. The intensity of macrophage infiltration was evaluated by immunochemistry, using the monoclonal antibody CD 68. The area of the plaque covered by macrophages was measured as a proportion of the whole plaque area, using a custom designed image tool analysis.

Results: Patients on statins had lower serum total cholesterol levels $(172 \pm 50$ vs $194 \pm 35 \mathrm{mg} / \mathrm{dl}, \mathrm{p}=0.014)$, lower low density cholesterol levels $(103 \pm 44$ vs $123 \pm 31 \mathrm{mg} / \mathrm{dl}, \mathrm{p}=0.010)$ and lower serum hsCRP levels $(1.8$ [1.1-3.4] vs 3.4 [1.3-4.9] $\mathrm{mg} / \mathrm{l}, \mathrm{p}=0.03$ ), while SAA, TNF $\alpha$, IL-6 and IL-1 $\beta$ levels did not differ between the 2 groups. The infiltration of atherosclerotic plaque by macrophages was similar in statin treated patients and in controls $(0.55 \pm 0.15 \%$ vs $0.49 \pm 0.19 \%, p=0.21)$.

Conclusion: Patients on statins have similar macrophage accumulation in their carotid atherosclerotic plaques compared with patients not on statins. Inflammatory markers were also similar in both groups except for hsCRP which was significantly lower in those taking statins.
\end{abstract}

Key Words: Statins, carotid endarterectomy, macrophages, high sensitivity C reactive protein, inflammation, cholesterol.

\section{INTRODUCTION}

The relationship between atherosclerosis and inflammation is well established [1-3]. Inflammation plays a role in plaque formation; even "early atherosclerosis", fatty streaks, consists of macrophage accumulation [4]. Inflammation also has a role in plaque destabilization and rupture $[5,6]$ since macrophages and other inflammatory molecules are increased in symptomatic plaques [7].

Treatment with statins is considered as first line therapy in atherosclerotic disease [8-15]. Statins also exert antiinflammatory effects [9-17].

The aim of this study was to evaluate the inflammatory burden in human carotid artery specimens as well as circulating inflammatory marker levels, in patients on statins and those not receiving these drugs.

*Address correspondence to this author at the Department of Vascular Surgery, Red Cross Hospital, Athens, Greece;

E-mail: paraskevask@hotmail.com

\section{PATIENTS AND METHODS}

We evaluated patients who underwent carotid endarterectomy for significant $(>70 \%)$ carotid bifurcation stenosis. The degree of stenosis was calculated using Digital Subtraction Angiography and the North America Symptomatic Carotid Endarterectomy Collaborators study [18] criteria of evaluation and measurement of carotid artery stenosis. The criteria for patient selection have been described [19].

All patients underwent a computerized tomographic brain study and were examined by the same neurologists. Based on data from history and clinical examination the patients were characterized as symptomatic or asymptomatic. Patients with amaurosis fugax, transient ischemic cerebral symptoms or ipsilateral ischemic stroke were characterized as symptomatic. The remaining patients were characterized as asymptomatic.

Initially, 119 patients scheduled to undergo carotid endarterectomy were evaluated. Five patients that began statin therapy less than 3 months before endarterectomy were excluded from the study. The remaining 114 consecutive pa- 
tients formed the study population. Fifty three (46\%) of them were on statin therapy at least 3 months before endarterectomy. The other $61(54 \%)$ patients had never received statins. The following statins were used: $26(47 \%)$ patients were on atorvastatin $(22 \pm 11 \mathrm{mg} /$ day $), 16(29 \%)$ on simvastatin $(27 \pm 10 \mathrm{mg} /$ day $), 8(15 \%)$ on pravastatin $(30 \pm 12 \mathrm{mg} /$ day $), 2$ $(4 \%)$ on lovastatin $(20 \mathrm{mg} /$ day $)$ and $1(2 \%)$ was on fluvastatin $(20 \mathrm{mg} /$ day $)$.

The study protocol was approved by the Red Cross Hospital Ethical Committee. Informed consent was obtained from all patients.

\section{LABORATORY ANALYSIS}

Blood samples were obtained from all patients the day before endarterectomy, after an overnight fast. The samples were centrifuged for $15 \mathrm{~min}$ at approximately $1000 \mathrm{~g}$. Serum was removed, aliquoted immediately and stored at $-70^{\circ} \mathrm{C}$ until tested. Part of the blood sample was used to measure common serum parameters and the lipid profile. Serum interleukin (IL)-1 $\beta$, IL-6 and tumor necrosis factor- $\alpha$ (TNF $\alpha$ ) concentrations were measured using quantitative sandwich enzyme immunoassay kits (Quantikine HS, R\&D Systems, Minneapolis, USA). The lower limit of detection was $<0.1$ $\mathrm{pg} / \mathrm{ml}$ for IL-1 $\beta, 0.04 \mathrm{pg} / \mathrm{ml}$ for IL-6 and $0.12 \mathrm{pg} / \mathrm{ml}$ for $\mathrm{TNF} \alpha$; high sensitivity C-reactive protein (hsCRP) and serum amyloid A (SAA) were assayed by high sensitivity particle enhanced immunonephelometry (N Latex, DateBehring Marburg GmbH, Marburg, Germany). The lower limit of detection was $0.18 \mathrm{mg} / 1$ for hsCRP and $0.8 \mathrm{mg} / \mathrm{l}$ for SAA. Values below the lower detection limit were considered as equal with this limit in the statistical analysis; there were no missing values. The coefficient variations for the assays used were for IL- $1 \beta$, IL- 6 , TNF $\alpha$, hsCRP and SAA $14 \%, 11 \%, 22 \%, 6 \%$ and $12 \%$, respectively. Homocysteine levels were determined using an enzymatic assay for the Hitachi 917 analyzer (Roche Diagnostics, Indianapolis, IN 46250, USA), as previously described [20].

\section{CAROTID ENDARTERECTOMY}

All carotid endarterectomy procedures were performed by 1 group of vascular surgeons at the Department of Vascular Surgery of the Red Cross Hospital in Athens, from June 2004 to May 2006. Immediately after carotid endarterectomy the specimen was transferred in $0.9 \%$ normal saline solution to the laboratory. Transverse sections $4 \mathrm{~mm}$ thick were prepared from each atherosclerotic lesion. The section containing the most stenotic part of the bifurcation was labelled 0 , while the consecutive parts distally were labelled $+1,+2,+3$ etc and proximally $-1,-2,-3$ etc. Each part was embedded in a different paraffin block. Sequential transverse sections 4 $\mu \mathrm{m}$ apart were obtained from each block and stained with haematoxylin and eosin. These sections were used for classification of the atherosclerotic plaque according to the American Heart Association (AHA) criteria [4].

\section{IMMUNOHISTOCHEMISTRY}

In order to measure macrophage infiltration of atherosclerotic plaques, we used monoclonal antibodies to a cell marker (CD68, Q-Bend Clone, Dako Corporation, Caprinteria, California, USA). Sequential sections $4 \mathrm{~mm}$ apart were evaluated from the atherosclerotic part of each specimen. The number of slides evaluated per patient was $4.1 \pm 2.4$ (mean $\pm \mathrm{SD}$ ). The whole plaque area, excluding parts of the specimen without obvious atherosclerotic lesions, was evaluated at $x 400$ magnification. Evaluation of the images was performed with the Image Tool analysis system (Image Pro Plus, Media Software, Cybernetics, Canada) by 2 independent examiners blinded to the clinical history, and the mean value was recorded. The results were expressed as the proportion of the whole plaque area stained with the monoclonal antibody CD 68.

\section{STATISTICAL ANALYSIS}

Continuous parameters are reported as mean \pm standard deviation, non parametric variables as median (interquartile interval) and categorical variables as percentages. The t-test or Mann-Whitney test was used for comparing continuous variables between 2 groups, as appropriate. Categorical variables were compared by the chi-square test or Fisher's exact test. The Spearman correlation test was used to assess relationships between variables. A $\mathrm{p}<0.05$ was considered significant.

\section{RESULTS}

Clinical and demographic characteristics of the study population are shown in Table $\mathbf{1}$. Statin treated patients had lower serum total cholesterol $(176 \pm 49$ vs $202 \pm 40 \mathrm{mg} / \mathrm{dl}$, $\mathrm{p}=0.011$ ) and low density lipoprotein cholesterol (LDL-C $103 \pm 46$ vs $127 \pm 34 \mathrm{mg} / \mathrm{dl}, \mathrm{p}<0.001)$ than patients not receiving these drugs. The 2 groups had no differences in AHA plaque classification and in procedural complications (data not shown).

hsCRP serum levels were significantly lower in patients on statins than in the controls (Table 2). The serum levels of SAA, TNF $\alpha$, IL- $1 \beta$ and IL- 6 did not differ between the 2 study groups (Table 2 ).

Patients on statin treatment had no differences in the lesion area covered by macrophages compared with patients not receiving these drugs $(0.55 \pm 0.15 \%$ vs $0.49 \pm 0.19 \%$, $\mathrm{p}=0.21$, data not shown). The interobeserver variability was moderate $(\kappa=0.61 \pm 0.09)$.

\section{DISCUSSION}

The main finding of this study is that patients on statins had the same degree of macrophage infiltration of their carotid atherosclerotic plaque with patients not receiving these drugs although serum hsCRP levels were significantly lower.

Several, but not all, studies favour the hypothesis that statins have beneficial effect on macrophage accumulation. Tahara et al. [21] using fluorodeoxyglucose positron emission tomography reported that simvastatin reduces the number of inflammation-rich atherosclerotic plaques compared with a placebo group. Crisby et al. [22] reported that patients pre-treated with pravastatin had less inflammation in their carotid arteries, compared with patients on placebo. Similar results were reported in monkeys, using simvastatin or pravastatin [23]. On the other hand, Verhoeven et al. [24] demonstrated that statin treated patients have increased amount of macrophages in their carotid endarterectomy specimens. However, in patients treated with atorvastatin, the increased amount of CD68 positive cells was not associated with increased protease activity [24]. Our findings are not consistent with either of these hypotheses, since we did 
Table 1. Clinical and Demographic Characteristics of the Statin and Control Groups

\begin{tabular}{|c|c|c|c|}
\hline & Statin Group & Control Group & $\mathbf{p}$ \\
\hline $\mathrm{n}$ & 53 & 61 & \\
\hline Duration of statin treatment (months) & $20 \pm 17$ & & \\
\hline \multicolumn{4}{|l|}{ Cardiovascular risk factors } \\
\hline Coronary artery disease & $13(25 \%)$ & $6(10 \%)$ & 0.07 \\
\hline Arterial Hypertension & $39(74 \%)$ & $49(80 \%)$ & 0.53 \\
\hline Diabetes mellitus & $15(28 \%)$ & $14(23 \%)$ & 0.66 \\
\hline Current cigarette smoking & $31(58 \%)$ & $38(62 \%)$ & 0.82 \\
\hline ARBs & $10(19 \%)$ & $13(21 \%)$ & 0.93 \\
\hline Beta-blockers & $18(38 \%)$ & $14(23 \%)$ & 0.27 \\
\hline Calcium channel blockers & $15(34 \%)$ & $27(44 \%)$ & 0.12 \\
\hline Diuretics & $10(19 \%)$ & $21(34 \%)$ & 0.08 \\
\hline Clopidogrel & $22(42 \%)$ & $24(39 \%)$ & 0.91 \\
\hline Aspirin & $23(43 \%)$ & $29(48 \%)$ & 0.67 \\
\hline Diabetes mellitus (oral drugs) & $12(22 \%)$ & $10(16 \%)$ & 0.61 \\
\hline Diabetes mellitus (insulin) & $2(4 \%)$ & $3(5 \%)$ & 0.91 \\
\hline Asymptomatic & $25(47 \%)$ & $32(52 \%)$ & 0.57 \\
\hline \multicolumn{4}{|l|}{ Serum parameters } \\
\hline Total Cholesterol (mg/dl) & $176 \pm 49$ & $202 \pm 40$ & 0.011 \\
\hline Low-density lipoprotein (mg/dl) & $103 \pm 46$ & $127 \pm 34$ & $<0.001$ \\
\hline High-density lipoprotein (mg/dl) & $38 \pm 6$ & $42 \pm 10$ & 0.16 \\
\hline Triglyceride (mg/dl) & $159 \pm 109$ & $154 \pm 66$ & 0.86 \\
\hline Apolipoprotein A (mg/dl) & $111 \pm 21$ & $118 \pm 24$ & 0.23 \\
\hline Apolipoprotein B (mg/dl) & $89 \pm 30$ & $96 \pm 26$ & 0.11 \\
\hline Lipoprotein (a) (mg/dl) & $48 \pm 52$ & $41 \pm 29$ & 0.87 \\
\hline Homocysteine $(\mu \mathrm{mol} / \mathrm{l})$ & $10.4 \pm 3.7$ & $13.0 \pm 5.1$ & 0.07 \\
\hline Creatinine (mg/dl) & $1.00 \pm 0.44$ & $1.03 \pm 0.47$ & 0.58 \\
\hline
\end{tabular}

ACE, Angiotensin converting enzyme; ARBs, Angiotensin receptor blockers.

not demonstrate any difference in macrophage infiltration between patients receiving statins and those not on these drugs.
hsCRP was lower in patients treated with statins, while the levels of SAA, TNF $\alpha$, IL- $1 \beta$ and IL- 6 were not different between the 2 groups. Statin-induced reduction in hsCRP 
Table 2. Serum Inflammatory Markers in Statin Treated and Control Patients with Carotid Bifurcation Disease

\begin{tabular}{|c|c|c|c|}
\hline Parameter & Statin Treated & Controls & P \\
\hline \hline IL-6 $(\mathrm{pg} / \mathrm{ml})$ & $2.5[1.8-4.1]$ & $2.9[1.9-5.2]$ & 0.24 \\
\hline TNF- $\alpha(\mathrm{pg} / \mathrm{ml})$ & $1.3[1.0-2.5]$ & $1.2[0.7-2.0]$ & 0.74 \\
\hline IL-1b $(\mathrm{pg} / \mathrm{ml})$ & $0.11[0.06-0.41]$ & $0.12[0.06-0.43]$ & 0.73 \\
\hline SAA $(\mathrm{mg} / \mathrm{l})$ & $10.3[4.6-22.1]$ & $11.2[3.8-23.6]$ & 0.48 \\
\hline hSCRP $(\mathrm{mg} / \mathrm{l})$ & $1.8[1.1-3.4]$ & $3.4[1.3-4.9]$ & 0.03 \\
\hline
\end{tabular}

IL-6, interleukin 6; TNF- $\alpha$, tumor necrosis factor- $\alpha$; IL-1b, interleukin $1 \mathrm{~b}$; SAA, serum amyloid A; hsCRP, high sensitivity C-reactive protein.

levels have been demonstrated in many studies in different patient populations [25-28]. The same is also true for SAA [29] although we did not observe this effect.

Statins are potent anti-inflammatory agents [2, 30-34]. The effect of statins on levels of inflammatory markers was evaluated in a group of hypercholesterolemic patients $(n=68)$ [35]. Compared with diet alone, an 8 -week regimen with atorvastatin plus diet recommendation was associated with a significant reduction in plasma levels of $\mathrm{TNF} \alpha(2.9 \%$ vs $21.4 \%$, respectively; p<0.0001), IL-6 (2.0\% vs $22.1 \%$, respectively; $\mathrm{p}<0.0001)$ and IL-1 (2.7\% vs $16.4 \%$, respectively; $\mathrm{p}<0.0001$ ) [35]. A similar association between statin use and reduction of $\mathrm{TNF} \alpha$ and IL-10 plasma levels was recently reported in patients with calcific aortic valve stenosis [36].

\section{STUDY LIMITATIONS}

This was a prospective cross sectional study comparing patients receiving statins for more than 3 months with patients who never received these drugs. The different statins, with varying dosage and treatment duration is a limitation. The possible effect of other drugs (like angiotensin converting enzyme inhibitors, angiotensin receptor blockers, betablockers and others) on macrophage accumulation also needs to be considered. The antibody CD68 used to validate macrophages is a non-selective macrophage marker and cannot express the complicated functional status of the macrophages [24]. We also do not know if more aggressive LDL-C lowering would change the results.

\section{CONCLUSIONS}

Patients on statins have no differences in macrophage accumulation in carotid atherosclerotic plaques compared with patients who never took these drugs. Inflammatory markers were similar in both groups except for hsCRP which was significantly lower in those individuals taking statins.

\section{REFERENCES}

[1] Ross R. Atherosclerosis: an inflammatory disease. N Engl J Med 1999; 340: 115-26.

[2] Athyros VG, Kakafika AI, Karagiannis A, et al. Do we need to consider inflammatory markers when we treat atherosclerotic disease? Atherosclerosis 2008; 200: 1-12.

[3] Libby P. Inflammation in atherosclerosis. Nature 2002; 420: 86874.

[4] Stary HC, Chandler AB, Dinsmore RE, et al. A definition of advanced types of atherosclerotic lesions and a histological classification of atherosclerosis: A report from the Committee on Vascular Lesions of the council on Arteriosclerosis, American Heart Association. Circulation 1995; 92: 1355-74.
[5] Schonbeck U, Mach F, Sukhova GK, et al. Regulation of matrix metalloproteinase expression in human vascular smooth muscle cells by $\mathrm{T}$ lymphocytes: a role for $\mathrm{CD} 40$ signaling in plaque rupture? Circ Res 1997; 81: 448-54.

[6] Newby AC, Zaltsman AB. Fibrous cap formation or destruction-the critical importance of vascular smooth muscle cell proliferation, migration and matrix formation. Cardiovasc Res 1999; 41: 345-60.

[7] Formato M, Farina M, Spirito R, et al. Evidence of a proinflammatory and proteolytic environment in plaques from endarterectomy segments of human carotid arteries. Arterioscler Thromb Vasc Biol 2004; 24: 129-35.

[8] Sacks FM, Pfeffer MA, Moye LA, et al. The effect of pravastatin on coronary events after myocardial infarction in patients with average cholesterol levels. Cholesterol and recurrent events trial investigators. N Engl J Med 1996; 335: 1001-9.

[9] Alnaeb ME, Alobaid N, Seifalian AM, et al. Statins and peripheral arterial disease: potential mechanisms and clinical benefits. Ann Vasc Surg 2006; 20: 696-705.

[10] Scandinavian Simvastatin Study Group. Randomized trial of cholesterol lowering in 4444 patients with coronary heart disease: The Scandinavian Simvastatin Study Group (4S). Lancet 1994; 344: 1383-9.

[11] Athyros VG, Mikhailidis DP, Papageorgiou AA, et al.; GREACE Collaborative Group. Effect of atorvastatin on high density lipoprotein cholesterol and its relationship with coronary events: a subgroup analysis of the GREek Atorvastatin and Coronary-heartdisease Evaluation (GREACE) Study. Curr Med Res Opin 2004; 20: 627-37.

[12] Athyros VG, Kakafika AI, Papageorgiou AA, et al. Effects of statin treatment in men and women with stable coronary heart disease: a subgroup analysis of the GREACE Study. Curr Med Res Opin 2008; 24: 1593-9.

[13] Tziomalos K, Athyros VG, Karagiannis A, et al. Endothelial function, arterial stiffness and lipid lowering drugs. Expert Opin Ther Targets 2007; 11: 1143-60.

[14] Shepherd J, Cobbe SM, Ford I, et al. Prevention of coronary heart disease with pravastatin in men with hypercholesterolemia. West of Scotland Coronary Prevention Study Group. N Engl J Med 1995; 333: 1301-7.

[15] Paraskevas KI, Hamilton G, Mikhailidis DP. Statins: an essential component in the management of carotid artery disease. J Vasc Surg 2007; 46: 373-86.

[16] Paraskevas KI, Tzovaras AA, Briana DD, et al. Emerging indications for statins: a pluripotent family of agents with several potential applications. Curr Pharm Des 2007; 13: 3622-36.

[17] Paraskevas KI, Liapis CD, Hamilton G, et al. Can statins reduce perioperative morbidity and mortality in patients undergoing noncardiac vascular surgery? Eur J Vasc Endovasc Surg 2006; 32: 28693.

[18] Clinical alert: benefit of carotid endarterectomy for patients with high-grade stenosis of the internal carotid artery. National Institute of Neurological Disorders and Stroke and Trauma Division. North American Symptomatic Carotid Endarterectomy Trial (NASCET) investigators. Stroke 1991; 22: 816-7.

[19] Koutouzis M, Nomikos A, Nikolidakis S, et al. Statin treated patients have reduced intraplaque angiogenesis in carotid endarterectomy specimens. Atherosclerosis 2007; 192: 457-63. 
[20] Hujigen HJ, Tegelaers FP, Schoenmakers CD, et al. Multicenter analytical evaluation of an enzymatic method for the measurement of plasma homocysteine and comparison with HPLC and immunochemistry. Clin Chem 2004; 50: 937-41.

[21] Tahara N, Kai T, Ishibashi M, et al. Simvastatin attenuates plaque inflammation J Am Coll Cardiol 2006; 48: 1825-31.

[22] Crisby M, Nordin-Fredriksson G, Shah PK, et al. Pravastatin treatment increases collagen content and decreases lipid content, inflammation, metalloproteinases, and cell death in human carotid plaques: implications for plaque stabilization. Circulation 2001; 103: 926-33.

[23] Sukhova GK, Williams JK, Libby P. Statins reduce inflammation in atheroma of nonhuman primates independent of effects on serum cholesterol. Arterioscler Thromb Vasc Biol 2002; 22: 1452-8.

[24] Verhoeven BA, Moll FL, Koekkoek JA, et al. Statin treatment is not associated with consistent alterations in inflammatory status of carotid atherosclerotic plaque: a retrospective study in 378 patients undergoing carotid endarterectomy. Stroke 2006; 37: 2054-60.

[25] Ridker PM, Rifai N, Pfeffer MA, et al. Long- term effects of pravastatin on plasma concentration of C-reactive protein. Circulation 1999; 100: 230-5.

[26] Standberg TE, Vanhanen H, Tikkanen MJ. Effect of statins on Creactive protein in patients with coronary artery disease. Lancet 1999; 353: 118-9.

[27] Paraskevas KI, Mikhailidis DP. C-reactive protein (CRP): more than just an innocent bystander? Curr Med Res Opin 2008; 24: 758 .

Received: November 10, 2008
[28] Blann AD, Gurney D, Hughes E, et al. Influence of pravastatin on lipoproteins, and on endothelial, platelet, and inflammatory markers in subjects with peripheral artery disease. Am J Cardiol 2001; 88: 89-92.

[29] Kinlay S, Schwartz GG, Olsson AG, et al. Myocardial Ischemia Reduction with Aggressive Cholesterol Lowering (MIRACL) study investigators. Circulation 2003; 108: 1560-6.

[30] Gelosa P, Cimino M, Pignieri A, et al. The role of HMG-CoA reductase inhibitors in endothelial dysfunction and inflammation. Vasc Health Risk Manag 2007; 3: 567-77.

[31] Forrester JS, Libby P. The inflammation hypothesis and its potential relevance to statin therapy. Am J Cardiol 2007; 99: 732-8.

[32] Stoll G, Bendszus M. Inflammation and atherosclerosis: novel insights into plaque formation and destabilization. Stroke; 37: 1923-32.

[33] Endres M. Statins: potential new indications in inflammatory conditions. Atheroscler Suppl 2006; 7: 31-5.

[34] Patel TN, Shishhbor MH, Bhatt DL. A review of high-dose statin therapy: targeting cholesterol and inflammation in atherosclerosis. Eur Heart J 2007; 28: 664-72.

[35] Ascer E, Bartolami MC, Venturinelli ML, et al. Atorvastatin reduces proinflammatory markers in hypercholesterolemic patients. Atherosclerosis 2004; 177: 161-6.

[36] Toli K, Paraskevas KI, Poulakou MV, et al. Association between plasma levels and immunolocalization of cytokines in heart valve lesions: a possible target for treatment? Expert Opin Ther Targets 2008; $12: 1209-15$

() Koutouzis et al.; Licensee Bentham Open.

This is an open access article licensed under the terms of the Creative Commons Attribution Non-Commercial License (http://creativecommons.org/licenses/by$\mathrm{nc} / 3.0 /$ ) which permits unrestricted, non-commercial use, distribution and reproduction in any medium, provided the work is properly cited. 